\title{
The Foundations of Latino Voter Partisanship: Evidence from the 2000 Election
}

\author{
R. Michael Alvarez \\ California Institute of Technology \\ Lisa García Bedolla \\ University of California, Irvine
}

\begin{abstract}
Studies of partisan identification in the U.S. have concentrated on Anglo Americans. We argue that by focusing only on the descendents of naturalized, mostly white, immigrants, that previous research may have been biased toward largely sociological accounts for the development of partisan attitudes. Here we study the partisan affiliations of Latino voters and argue that by examining their partisan attitudes we should find that their partisanship is more explicitly political than Anglos. We utilize a telephone survey of Latino likely voters in the 2000 presidential election and find that Latino voter partisanship is shaped by both political and social factors.
\end{abstract}

he 2000 presidential election saw unprecedented appeals by both the Bush and Gore campaigns for Latino votes. Both campaigns used Spanish language advertisements and made special efforts to establish connections with Latino political and media elites. This is not surprising on the part of the Democrats since the Latino community has historically voted strongly Democratic (DeSipio 1996; de la Garza, García, and DeSipio 1992; García and de la Garza 1977). But by making a direct effort to court the Latino vote, Republicans in 2000 clearly believed they could make significant inroads into this segment of the electorate. Many Republicans, especially in the Southwest, continue to argue that Latino socioeconomic mobility and social conservatism make them ripe for Republican "conversion."

An earlier version of this paper was presented at the 2001 annual meeting of the Western Political Science Association in Las Vegas. We acknowledge the Knight-Ridder News Organization, in particular its Washington bureau; the San Jose Mercury News; the Fort Worth Star-Telegram; and the Miami Herald for providing us with the 2000 Voter Survey. Specifically we thank Nadine Selden and Mary Anne Ostrom of Knight-Ridder for their assistance. We thank Jonathan Nagler for his assistance and Gary Segura and Louis DeSipio for helpful comments on earlier versions of this paper. Michael Alvarez thanks the IBM Corp. for research support.

THE JOURNAL OF POLITICS, Vol. 65, No. 1, February 2003, Pp. 31-49

(C) 2003 Southern Political Science Association 
This belief on the part of Republican strategists raises a number of important research questions. First, has Democratic partisanship in the Latino electorate eroded to the point where a sizeable number of Latino votes can be won by Republican appeals? Second, are Latino voter party identifications more malleable and potentially influenced by short-term political and economic factors than those of other groups? Much of the early work argued that partisanship is a long-term and stable political affiliation, not easily altered by political campaigns or direct issue appeals (Campbell et al. 1960; Miller and Shanks 1996). Is this true for the Latino electorate, or is the Latino political experience so different from the dominant Anglo experience to render moot generalizations from earlier studies of Anglo political affiliations to the Latino electorate?

We argue that Latinos constitute an important demographic group and that the study of their partisan and other political attitudes provides critical tests of existing political theory (García Bedolla 1999; Hero 1992). The Latino population in the United States contains three main groups: non-naturalized immigrants; naturalized immigrants; and the native born, which include the descendents of immigrants and those present in the Southwest at the time of annexation. Most research on political attitudes in the United States has focused on Anglo Americans, who look most like the third group, the native born. But by focusing only on the descendents of naturalized, largely white, immigrants, previous party identification research may have been biased toward sociological explanations, given that the mostly Anglo respondents had had longer socialization experiences in America. In contrast, newly naturalized American citizens often enter American politics without well-formed political attitudes learned through social mechanisms. Thus, it is possible that immigrant Latinos might initially develop their partisanship through more explicitly political means than Anglos.

These important research questions form the basis for the research we report in this article. Using a telephone survey of Latino likely voters during the 2000 election, we examine the correlates of Latino voter partisanship in this most recent election. In the next section, we discuss the literature on partisanship and the underlying logic for the model we test. Then we outline the data set we use and discuss our basic methodology. Next, we present our results, and we conclude that Latino voter partisanship is influenced most by political and social factors.

\section{Party Identification and Latinos}

The main debate regarding the nature of partisanship in American politics has centered on how stable partisan attachments are over time. This debate originates in The American Voter, where Campbell et al. (1960) posited a political socialization model of partisanship: party identification constitutes an affective attachment to a social group, in this case a party. These attachments are learned early in life, often at a pre-political age, and remain stable over time (Abramson and 
Ostrom 1991; Green and Palmquist 1990; Miller 1991). In this model, change results from great personal changes, like marriage, or from exceptional political changes, such as the Civil War. Since these events do not happen often, they see political events as having little effect on the evolution of an individual's party identification.

Revisionists have argued that party identification is not nearly as stable as the traditionalists have led us to believe and that identification is more malleable than the traditional model has assumed (Fiorina 1981; Franklin 1984; Franklin and Jackson 1983; Markus and Converse 1979; McKuen, Erikson, and Stimson 1989). These scholars see party identification as a more dynamic process, driven by issues ranging from retrospective political and economic evaluations (Fiorina), past votes (Markus and Converse), and policy perspectives (Franklin and Jackson). While they may disagree on the agents driving change, they argue that political events do affect the nature and strength of party identification and that Americans sometimes do switch their party affiliation during their lifetimes.

Despite the fact that partisan identification is a key element of American political behavior, we know little about the nature and stability of Latino party identification. Studies of partisanship in the United States have generally relied on national data sets like the American National Election Study (ANES) and Gallup Polls that contain few Latinos. Most of the studies that have examined Latino political behavior have had either relatively small samples or samples that are not nationally representative, rendering generalizations problematic (Brischetto 1987; Cain, Kiewiet, and Uhlaner 1991; Kosmin and Keysar 1995; Welch and Sigelman 1993). One exception is Uhlaner, Gray, and García (2000), who, using the Latino National Political Survey (LNPS), a nationally representative sample, find that policy positions affect Latino party identification more than ideology or demographic variables like education and income (see also Uhlaner and García 2001). Since the LNPS was conducted in 1989-1990, the 2000 Latino Voter Survey provides an important basis from which we can assess changes, if any, in Latino partisanship over the last decade and use this analysis as a bridge to the larger literature on partisanship.

As we saw above, studies of party identification have found three kinds of factors affecting the nature and stability of party identification: social issues and a person's socialization process, the nature of the political environment and resulting policy preferences, and economic status. To determine which is most salient for Latinos, we develop a fully specified model that looks at the effects of social, political, and economic factors on Latino partisanship. Yet, it is important to note that previous research about Latino party identification said little about the causal relationship among these factors, a topic that has been of concern in research about partisanship in American political life (see especially Franklin and Jackson 1983; Markus and Converse 1979; and Page and Jones 1979). In this analysis, we follow previous studies of Latino partisanship and examine causal flow only in one direction - we look at the impact of issue, economic, and demographic factors on partisanship and not the reverse. While this does risk potential biases 
in our multivariate analysis if our assumption of unidirectional causation is incorrect, we wish to maintain continuity with past research so that our results can be easily compared to those from the 1989-1990 LNPS. In addition, we are concerned that current methodological tools do not allow for easy or accurate estimation of multi-equation causal models with discrete dependent variables. ${ }^{1}$

\section{Survey Methodology and Research Design}

To test our model, we use the 2000 Latino Voter Study conducted by the Knight-Ridder News Organization, which interviewed 2,721 likely Latino voters from May 26, 2000, through June 15, 2000. ${ }^{2}$ The survey was conducted in English and Spanish, and the telephone interviewing was done by International Communications Research of Media, Pennsylvania. The sample contains 611 respondents from California, 600 from Texas, 608 from Florida, and 600 from New Yorkthe four states with the largest populations of Latino voters. Interviews were also conducted with 302 Latinos from eight other states: New Jersey, New Mexico, Arizona, Colorado, Illinois, Pennsylvania, Michigan, and Connecticut. Overall, these twelve states contain approximately $90 \%$ of the national population of registered Latino voters, ensuring this survey is nationally representative of the Latino electorate. The sample's national margin of error was $2 \%$. The survey restricted interviewing to likely Latino voters, limiting our hypothesis testing to only Latinos who are registered and likely to vote. ${ }^{3}$ This data set also restricts our analysis in another way because members of other racial and ethnic groupsAnglos, African Americans, Asian Americans, and others-were not interviewed as part of this study. ${ }^{4}$ Yet, despite its limitations, this data set is the largest and most recent study available to examine the political attitudes of the group being courted by both political parties: Latino likely voters.

\footnotetext{
${ }^{1}$ Alvarez and Glasgow (2000) conclude their discussion of the methodology for estimating nonrecursive models with one binary and one continuous dependent variable: "More work on estimation techniques for other types of nonrecursive models, involving different types of discrete dependent variables, is needed. Unfortunately, little is known about the finite sample properties of nonrecursive choice models with discrete dependent variables" (164). We prefer to wait for the development of appropriate methodological techniques before attempting to estimate a nonrecursive model of Latino party identification.

${ }^{2} \mathrm{~A}$ collection of the major stories written using this survey data set can be found at http://www0.mercurycenter.com/local/center/lpoll0723.htm.

${ }^{3}$ Only registered Latinos were contacted. A five-question filter determined who were "likely voters": respondents had to state that they were 18 years of age or older; were willing to conduct an interview in English or Spanish; considered him or herself of Latino or Hispanic origin; were registered in the local precinct or election district; and were extremely likely, very likely, or somewhat likely to "vote in the upcoming election for president on November 7." If a respondent failed any of these stages, the interview was terminated.

${ }^{4}$ A direct comparison, then, of factors that might influence Latino partisanship differently than that of other racial and ethnic groups is impossible with this particular survey. This is an obvious question for future research.
} 
The dependent variable in our analysis is the respondent's stated partisan affiliation. The 2000 Latino Voter Survey used a standard question to assess partisan affiliation: "Generally speaking, do you think of yourself as a Democrat, a Republican, an independent, or something else?" This survey did not ask respondents about the strength of their partisan affiliations. ${ }^{5}$

From this questionnaire, we used three sets of variables to test our main hypotheses about Latino partisanship in the 2000 election: social and demographic questions, political and issue questions, and economic status questions. Our measurement of these factors is based on a series of variables taken from the survey. A full description of the coding of the variables is located in Appendix A. In terms of social/demographic factors, we include variables for ethnic origins, including national origin and whether or not the respondent was foreign born. We also look at the effect of marital status, educational attainment, education, age, gender, religion, and primary language spoken at home. To measure the impact of political issues, we include indicators of the respondents' opinions on seven policy issues: abortion, illegal immigration, affirmative action, school vouchers, government-sponsored health insurance, use of the government surplus, and gun control. We also included measures for ideology and whether the respondent was a new voter. Lastly, we have two economic measures in our model: a measure of retrospective economic perceptions and the respondent's family income.

Thus, our model of Latino voter partisanship takes the following functional form:

\section{$P I D=F($ Social and Demographic Factors, Political Opinions and}

\section{Behavior and Economic Perceptions and Income).}

As our dependent measure for partisanship is a categorical variable, based on whether the voter identified as a Democrat, Republican or independent, we used multinomial logit to estimate the effect of each independent measure on the relative probability that a voter would identify as an independent or Democrat, or as a Republican or Democrat. ${ }^{6}$ The multinomial logit estimates allow for tests of

\footnotetext{
${ }^{5}$ Our analysis examines only the direction of Latino voter partnership, and not the strength. While earlier studies have looked at strength of Latino voter partnership (e.g., Uhlaner and García 2001), we restrict our focus to direction since it is the more politically relevant issue regarding Latino voter partisanship. By not studying strength we also sidestep the methodological debates over whether partisanship is a unidimensional or multidimensional type of attitude for Latino voters (see Alvarez 1990; Green 1988).

${ }^{6}$ For detailed discussion of the multinomial logit model, see Aldrich and Nelson (1984), Greene (2000), or Long (1997). The basic idea behind the multinomial logit model is that we observe discrete and unordered outcomes. We specify the probability that each individual picks from one of the set of outcomes as:
}

$$
\begin{aligned}
& \operatorname{Pr}(y=1)=\left(\exp ^{X \beta(1)}\right) /\left(\exp ^{X \beta(1)}+\exp ^{X \beta(2)}+\exp ^{X \beta(3)}\right) \\
& \operatorname{Pr}(y=2)=\left(\exp ^{X \beta(2)}\right) /\left(\exp ^{X \beta(1)}+\exp ^{X \beta(2)}+\exp ^{X \beta(3)}\right) \\
& \operatorname{Pr}(y=3)=\left(\exp ^{X \beta(3)}\right) /\left(\exp ^{X \beta(1)}+\exp ^{X \beta(2)}+\exp ^{X \beta(3)}\right)
\end{aligned}
$$


the effects of each specific measure relative to other measures within the same explanatory model (for example, for the impact of affirmative action opinions relative to other political opinions) and across explanatory models (for example, looking at the impact of affirmative action opinions relative to social factors like age). Unfortunately, since the multinomial logit model produces estimates that are nonlinear (the impact of a particular variable depends on the values of the other variables in the model), they can be difficult to understand. So we transform the multinomial logit parameters into odds ratios. The odds ratio (also known as the relative risk ratio) is a measure of the relative odds of one outcome being chosen relative to the baseline outcome, for a one-unit change in one of the right-hand side variables. ${ }^{7}$

We also use the multinomial logit model to test the explanatory power of each group of variables separately—social, political, and economic. ${ }^{8}$ Finally, in order

where we have the outcomes coded 1, 2, and 3 (say, for example, as corresponding to Democratic, Republican, or independent identification). Unfortunately, this model as specified above is not identified, so we "normalize" one of the parameter vectors (say for choice 1) to be equal to 1 :

$$
\begin{aligned}
& \operatorname{Pr}(y=1)=(1) /\left(1+\exp ^{X \beta(2)}+\exp ^{X \beta(3)}\right) \\
& \operatorname{Pr}(y=2)=\left(\exp ^{X \beta(2)}\right) /\left(1+\exp ^{X \beta(2)}+\exp ^{X \beta(3)}\right) \\
& \operatorname{Pr}(y=3)=\left(\exp ^{X \beta(3)}\right) /\left(1+\exp ^{X \beta(2)}+\exp ^{X \beta(3)}\right)
\end{aligned}
$$

These probabilities are easily estimated by maximization of the following log-likelihood function:

$$
\ln L=\sum_{i=1}^{n} \sum_{j=0}^{J} d_{i j} \ln \operatorname{Pr}\left(y_{i}=j\right)
$$

where $j$ is the number of choices, $i$ denotes an individual, and $n$ is the number of individuals in the sample. Estimation produces the relative probabilities that an individual would pick outcome 2 relative to 1 , and outcome 3 relative to 1 , given their $X$ values.

${ }^{7}$ Recall from above that the probabilities for choosing outcomes 1 or 2 are:

$$
\begin{aligned}
& \operatorname{Pr}(y=1)=(1) /\left(1+\exp ^{X \beta(2)}+\exp ^{X \beta(3)}\right) \\
& \operatorname{Pr}(y=2)=\left(\exp ^{X \beta(2)}\right) /\left(1+\exp ^{X \beta(2)}+\exp ^{X \beta(3)}\right)
\end{aligned}
$$

Thus, the relative probability of choosing outcome 2 relative to the baseline category (1) is:

$$
\operatorname{Pr}(y=2) / \operatorname{Pr}(y=1)=\exp ^{X \beta(2)}
$$

This is the odds or relative risk ratio (Greene 2000; Long 1997). The odds or relative risk ratio for a one unit change in one of the right-hand side variables can easily be written from these expressions as the exponentiated value of the respective coefficient: $\exp ^{\beta(2)}$. We present the odds ratios in this article because they are easy to compute and are readily understandable.

${ }^{8}$ This stems from a simple but important fact about maximum likelihood estimation of multinomial logit models. We first estimate the log-likelihood of a fully specified model (that is, a model with all of the right-hand side variables included), and we obtain the value of the log-likelihood function at convergence. We can respecify the model to include only a subset of the right-hand side variables, called the constrained model; estimation of the constrained model yields a second log-likelihood value at convergence. The ratio of these two log-likelihoods has a convenient statistical distribution that lets us test for whether they are statistically distinct-in other words, does the addition of the variables not in the constrained model add to the explanatory power of the fully specified model? For details of the likelihood ratio test, see Greene (2000, 152-153). 
to provide a better sense of how these probabilities would operate in the "real world," we use our multinomial logit estimates to look at how change in one independent variable would affect the probability that a "hypothetical" Latino voter would identify with a particular party, holding all else constant. We discuss these results in the next section.

\section{Testing the Explanatory Models}

We begin by examining the distribution of party identification in our sample. In the entire sample of Latino voters, $56.6 \%$ reported Democratic affiliation, while less than half of that amount reported Republican affiliation (24.5\%). Just over $13 \%$ reported that they were independents $(13.2 \%)$, while $5.7 \%$ said they were affiliated with no political party $(4.6 \%)$ or some other third party $(1.1 \%)$. In comparison with voters from the 2000 American National Election Study (ANES), 77\% of whom were Anglo, 50\% stated Democratic identification, $42 \%$ stated Republican identification, and $8 \%$ were either independent or apolitical. ${ }^{9}$ Thus, Latino voters in the 2000 election were slightly more Democratic in identification than the most recent ANES sample of voters, and much less Republican.

In Table 1 we provide the breakdown of Latino voter identification by national origin, Mexicans, Cubans, Puerto Ricans, and Central Americans, and compare it to findings for registered voters from the LNPS. We find that Latino partisanship has not changed dramatically over the last decade. Mexican-origin partisanship has remained remarkably stable, with about $67 \%$ of respondents reporting Democratic affiliation and about 13\% Republican affiliation in both surveys. Cuban-origin Latino voters, on the other hand, have become somewhat more Republican: $66.7 \%$ in the LNPS reported Republican partisanship, while almost $70 \%$ of Cuban voters in the Latino Voter Survey stated Republican identification. Puerto Ricans have also become slightly less Democratic, moving from $69.3 \%$ in the LNPS to $64.4 \%$ of the respondents in this sample. Central Americans, who were not part of the LNPS, are strongly Democratic in this sample, with 57\% stating Democratic identification. While the LNPS and 2000 Voter Survey are not exactly comparable in their sampling methods and question wording, the comparison of findings from the two surveys suggests that, as has been found in macropartisanship studies generally, Latino partisanship within national origin groups has been fairly stable over the last decade (Box-Steffensmeier and Smith 1996; Green and Palmquist 1990; Miller 1991).

Now we turn to our model, which we use to test the impact of each of the independent variables, controlling for all other possible impacts, and we present these

\footnotetext{
${ }^{9}$ The ANES estimates provide the partisanship for all respondents who said they voted in the 2000 presidential election, in the postelection interview. The preelection interview included a question that asked respondents to say how likely they were to vote (the closest approximation to a likely voter filter in the ANES): $51 \%$ of likely voters in the ANES stated Democratic partisanship, 39\% Republican, and $9 \%$ were independent or apolitical.
} 


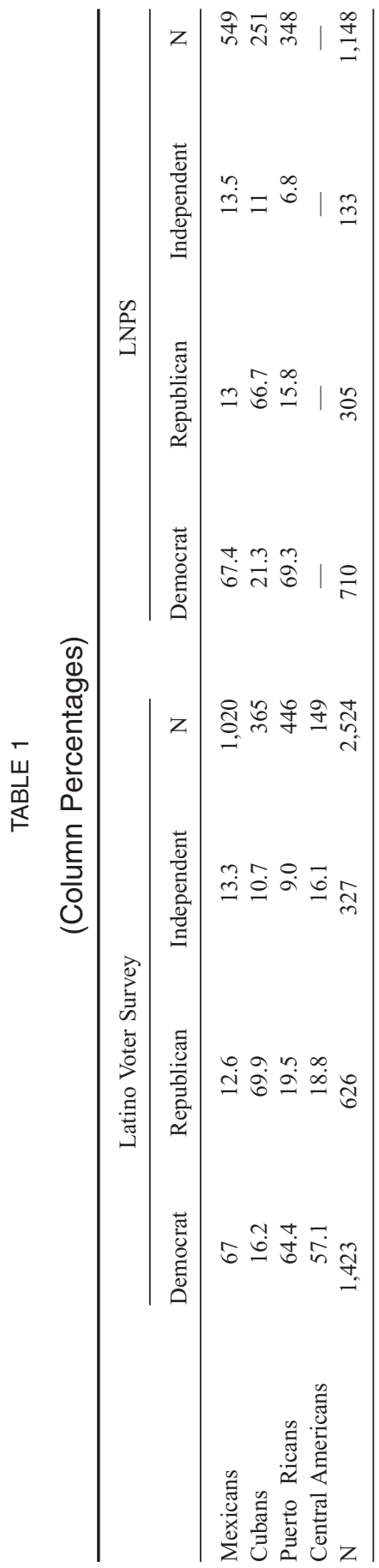

This content downloaded from 131.215.225.150 on August 07, 2017 15:13:51 PM All use subject to University of Chicago Press Terms and Conditions (http://www.journals.uchicago.edu/t-and-c). 
TABLE 2

Latino Party Identification Model

\begin{tabular}{|c|c|c|c|c|}
\hline & \multicolumn{2}{|c|}{ PR (Ind) v. PR (Dem) } & \multicolumn{2}{|c|}{ PR (Rep) v. PR (Dem) } \\
\hline & MNL & Odds Ratio & MNL & Odds Ratio \\
\hline \multirow[t]{2}{*}{ Foreign Born } & -.06 & .94 & .18 & 1.19 \\
\hline & $(.20)$ & (.19) & $(.20)$ & $(.24)$ \\
\hline \multirow[t]{2}{*}{ Cuban } & $.86^{*}$ & $2.35^{*}$ & $2.44 *$ & $11.45^{*}$ \\
\hline & $(.32)$ & $(.76)$ & $(.26)$ & $(3.03)$ \\
\hline \multirow[t]{2}{*}{ Mexican } & $-.34 *$ & $.71 *$ & $-.51 *$ & $.60^{*}$ \\
\hline & $(.20)$ & $(.15)$ & $(.21)$ & $(.13)$ \\
\hline \multirow[t]{2}{*}{ Puerto Rican } & $-.16^{*}$ & $.86^{*}$ & -.08 & .93 \\
\hline & $(.09)$ & $(.07)$ & $(.08)$ & $(.08)$ \\
\hline \multirow[t]{2}{*}{ Married } & -.18 & .84 & .19 & 1.21 \\
\hline & $(.19)$ & $(.16)$ & (.19) & $(.23)$ \\
\hline \multirow[t]{2}{*}{ Some HS } & $-.58 *$ & $.56^{*}$ & $-.79 *$ & $.45^{*}$ \\
\hline & $(.34)$ & $(.19)$ & $(.31)$ & $(.14)$ \\
\hline \multirow[t]{2}{*}{ High School } & -.37 & .69 & $-.54 *$ & $.58^{*}$ \\
\hline & $(.26)$ & $(.18)$ & $(.25)$ & $(.15)$ \\
\hline \multirow[t]{2}{*}{ Some College } & -.28 & .75 & -.30 & .74 \\
\hline & $(.26)$ & $(.20)$ & $(.25)$ & (.19) \\
\hline \multirow[t]{2}{*}{ 2-Year College } & -.20 & .82 & -.04 & .96 \\
\hline & $(.27)$ & $(.22)$ & $(.26)$ & $(.25)$ \\
\hline \multirow[t]{2}{*}{$18-30$} & .16 & 1.18 & .49 & 1.63 \\
\hline & (.33) & $(.39)$ & $(.32)$ & $(.52)$ \\
\hline \multirow[t]{2}{*}{$31-45$} & .05 & 1.05 & .15 & 1.16 \\
\hline & $(.27)$ & $(.28)$ & $(.25)$ & $(.29)$ \\
\hline \multirow[t]{2}{*}{$46-60$} & .14 & 1.15 & -.09 & .92 \\
\hline & $(.27)$ & $(.31)$ & $(.25)$ & $(.23)$ \\
\hline \multirow[t]{2}{*}{ Women } & $-.37 *$ & $.69^{*}$ & -.03 & .97 \\
\hline & $(.18)$ & $(.12)$ & $(.17)$ & $(.16)$ \\
\hline \multirow[t]{2}{*}{ Catholic } & .10 & 1.10 & .02 & 1.02 \\
\hline & $(.19)$ & $(.21)$ & (.18) & (.18) \\
\hline \multirow{2}{*}{ Spanish } & -.42 & .66 & -.12 & .89 \\
\hline & $(.25)$ & $(.17)$ & $(.24)$ & $(.21)$ \\
\hline \multirow[t]{2}{*}{ Spanish-English } & -.06 & .95 & -.16 & .86 \\
\hline & $(.21)$ & $(.20)$ & $(.21)$ & $(.18)$ \\
\hline \multirow[t]{2}{*}{ Abortion } & -.04 & .96 & $-.39 *$ & $.68^{*}$ \\
\hline & $(.12)$ & $(.11)$ & $(.12)$ & $(.08)$ \\
\hline \multirow[t]{2}{*}{ Illegal Immigration } & -.05 & .95 & -.12 & .88 \\
\hline & (.11) & (.11) & (.11) & $(.10)$ \\
\hline \multirow[t]{2}{*}{ Affirmative Action } & $-.20 *$ & $.82 *$ & $-.27 *$ & $.76^{*}$ \\
\hline & $(.09)$ & $(.08)$ & $(.09)$ & $(.07)$ \\
\hline \multirow[t]{2}{*}{ School Vouchers } & $-.49 *$ & $.61 *$ & $-.63 *$ & $.53^{*}$ \\
\hline & $(.18)$ & $(.11)$ & $(.17)$ & $(.09)$ \\
\hline \multirow[t]{2}{*}{ Gov't Health Insurance } & -.43 & .65 & $-1.22 *$ & $.30 *$ \\
\hline & $(.28)$ & $(.18)$ & $(.24)$ & $(.07)$ \\
\hline \multirow[t]{2}{*}{ Gun Control } & .05 & 1.05 & $-.20 *$ & $.82 *$ \\
\hline & (.09) & $(.10)$ & $(.08)$ & $(.07)$ \\
\hline
\end{tabular}

This content downloaded from 131.215.225.150 on August 07, 2017 15:13:51 PM All use subject to University of Chicago Press Terms and Conditions (http://www.journals.uchicago.edu/t-and-c). 
TABLE 2 continued

\begin{tabular}{|c|c|c|c|c|}
\hline & \multicolumn{2}{|c|}{ PR (Ind) v. PR (Dem) } & \multicolumn{2}{|c|}{ PR (Rep) v. PR (Dem) } \\
\hline & MNL & Odds Ratio & MNL & Odds Ratio \\
\hline Budget-Tax Cuts & $\begin{array}{c}.68 * \\
(.33)\end{array}$ & $\begin{array}{l}1.97 * \\
(.64)\end{array}$ & $\begin{array}{c}.47 \\
(.30)\end{array}$ & $\begin{array}{l}1.60 \\
(.48)\end{array}$ \\
\hline Budget-Debt Reduction & $\begin{array}{c}.35 \\
(.26)\end{array}$ & $\begin{array}{l}1.42 \\
(.37)\end{array}$ & $\begin{array}{c}-.03 \\
(.26)\end{array}$ & $\begin{array}{c}.97 \\
(.25)\end{array}$ \\
\hline Budget_-Domestic Spending & $\begin{array}{c}-.15 \\
(.20)\end{array}$ & $\begin{array}{c}.86 \\
(.17)\end{array}$ & $\begin{array}{c}-.33 * \\
(.19)\end{array}$ & $\begin{array}{l}.72 * \\
(.14)\end{array}$ \\
\hline Liberal & $\begin{array}{c}-.65^{*} \\
(.20)\end{array}$ & $\begin{array}{l}.52^{*} \\
(.11)\end{array}$ & $\begin{array}{c}-.67 * \\
(.23)\end{array}$ & $\begin{array}{l}.51^{*} \\
(.12)\end{array}$ \\
\hline Conservative & $\begin{array}{c}-.20 \\
(.21)\end{array}$ & $\begin{array}{c}.83 \\
(.17)\end{array}$ & $\begin{array}{l}.74 * \\
(.19)\end{array}$ & $\begin{array}{c}2.09^{*} \\
(.39)\end{array}$ \\
\hline New Voter & $\begin{array}{c}.58^{*} \\
(.24)\end{array}$ & $\begin{array}{l}1.79 * \\
(.44)\end{array}$ & $\begin{array}{c}.19 \\
(.26)\end{array}$ & $\begin{array}{l}1.21 \\
(.31)\end{array}$ \\
\hline Economic Perceptions & $\begin{array}{c}-.12 \\
(.09)\end{array}$ & $\begin{array}{c}.89 \\
(.08)\end{array}$ & $\begin{array}{c}-.18^{*} \\
(.08)\end{array}$ & $\begin{array}{c}.83^{*} \\
(.07)\end{array}$ \\
\hline Income & $\begin{array}{c}.01 \\
(.06)\end{array}$ & $\begin{array}{l}1.01 \\
(.06)\end{array}$ & $\begin{array}{c}.02 \\
(.06)\end{array}$ & $\begin{array}{l}1.03 \\
(.06)\end{array}$ \\
\hline Constant & $\begin{array}{c}.98 \\
(.70)\end{array}$ & & $\begin{array}{l}3.03 \\
(.64)\end{array}$ & \\
\hline
\end{tabular}

$\mathrm{PR}=$ probability

Standard errors are in parentheses
$\mathrm{MNL}=$ Multinomial logit coefficient.

* significant at $p<.05$ level, one-tailed test.

results in Table 2. Our multinomial logit model fits the data well, with a model chi-square of 338.50 and a correct classification rate of $71.2 \%$.

Beginning with the results for choosing independence versus Democratic identification, we see first that the national origin variables are statistically significant: Mexican- and Puerto Rican-origin Latino voters are less likely to be independent than Democratic, but Cubans are more likely to be independent than Democratic. On the political side, school vouchers opponents, liberals, and not newly mobilized Latino voters are all more likely to be Democratic than independent.

Next, in the Republican versus Democratic identification results, we see both national origin and education effects continue to be statistically significant: Cubans are more likely to be Republican than Democratic, while Mexicans are more likely to be Democratic than Republican, controlling for all other social, economic, and political factors. This is similar to Uhlaner and García's (2001) findings from the LNPS and suggests that national origin has an important and independent effect on Latino party identification. Regarding education, we see that Latino voters at the lower rungs of the educational attainment ladder are more likely to be Democratic than Republican, all things constant. 
In addition, many of the political variables are significant in the fully specified model. Of the issues, abortion, affirmative action, school vouchers, and government-funded health insurance all have statistically significant effectseach is negatively signed, meaning that Latino voters with more liberal opinions are more likely to be Democratic than Republican. We also see significant results for ideological beliefs, with liberals more likely to be Democratic and conservatives more likely to be Republican. ${ }^{10}$

With regard to the economic variables in our model, we find that economic perceptions have a statistically significant impact on the choice between Democratic and Republican partisanship. More positive economic perceptions lead Latino voters to assume Democratic affiliations, while more negative perceptions lead them to Republican identities. But consistent with the findings of other studies of Latino partisanship, and in contrast to findings for Anglos, income does not have a significant effect on Latino partisanship (Cain, Kiewiet, and Uhlaner 1991; Nicholson and Segura 2001; Uhlaner and García 2001).

Overall, in terms of the relative magnitudes of the impact of different independent variables in our model, we find that in the first equation (independent versus Democratic identification), the strongest predictive variable is that for the new voters, followed by the national origin and issue opinion variables. In the second equation (Republican versus Democratic identification), we find that by far the strongest predictive variable is Cuban origin. The second strongest significant predictive factor is conservative ideology, followed by the other significant effects in this model.

Since the partisanship literature suggests social, political, and economic factors may each have an independent effect on party identification, we also ran three different models - one with just the social variables, one with the political, and one with the economic - and test the restriction that each set of variables has no impact on partisanship. We present the results of these chi-square tests in Table 3 .

The basic conclusion that is clear from Table 3 is that the social and political models of Latino voter partisanship have stronger predictive power than the economic model. Both the social and political models of partisanship have strong and roughly similar chi-square values (181.24 for the social model and 179.73 for the political model), and the $p$-value for each test is less than .00 , which is highly significant, controlling for degrees of freedom (the number of parameters in each test restricted to 0 ). However, the chi-square value for the economic model is not strong (5.70) and is significant only at the $p<.14$ level, which is greater than conventional levels of statistical significance, but not as strong as the other

\footnotetext{
${ }^{10}$ Identifying the array of Latino voter opinion on each of these policy issues, and how those opinions vary across ethnic identities, is an important question that is beyond the scope of the present research. Some analysis of the issue opinions is reported at $<\mathrm{http} / /$ www0.mercurycenter.com/local/center/polldata.htm $>$, and in future research we will undertake further analysis of issue opinions and their variance across national origin groups.
} 
TABLE 3

Summary of MNL Results

\begin{tabular}{lccc}
\hline & Social & Political & Economic \\
\hline Chi-Square & 181.24 & 179.73 & 5.70 \\
$p$-Value & .00 & .00 & .14 \\
Degrees of Freedom & 32 & 24 & 4 \\
\hline
\end{tabular}

models. Thus, while economic factors do "matter" in our model of Latino voter partisanship, we conclude that Latino voter partisanship can best be explained by social and political factors. ${ }^{11}$

This analysis does not shed much light, however, on the "real world" political questions we discussed at the beginning of this article. If social and political factors are most important to Latino partisanship, what social and political factors would have to change before we would begin to see wholesale "conversion" of Latinos from one political party to another? To address this question, we ran probability estimates to see what effect changes in particular economic and political characteristics could be expected to have on Latino partisanship. Table 4 provides a summary of these probability estimates.

Our "hypothetical" Latino voter is of Cuban or of Mexican national origin, is the demographic average for the community-is unmarried, has a high school education, is in the 18-30 age range, is male and Catholic, speaks English at home - and has status quo issue opinions regarding abortion, illegal immigration, affirmative action, school vouchers, government-funded health insurance, and handgun control. He does not believe that the budget surplus should be used for tax cuts, debt reduction, or increased social spending, identifies with a conservative ideology, is a newly mobilized voter, perceives his family's economic circumstances as unchanged in the past year, and is of moderate income $(\$ 25,000$ to $\$ 35,000)$.

Given the "hypothetical" Latino voter, computing these probability estimates is a matter of simply using the multinomial logit model estimates from the full specification and the independent variable values implied by the assumed typical or hypothetical voter. We then compute the estimated probability that either the Cuban origin or Mexican origin voter would identify with the Democratic or Republican parties, or as an independent - this is the "baseline" probability estimate. We then change one of the independent variables to another value and

\footnotetext{
${ }^{11}$ Unfortunately, the questions included in the Knight-Ridder survey limit our ability to assess the impact of broader economic perceptions (other simple retrospective evaluations) or mediated retrospective evaluations. As a result, our specification of the economic or retrospective model of partisanship falls far short of the broader model advocated by proponents of the economic model of partisanship (e.g., Fiorina 1981). We hope that future studies of Latino political behavior will incorporate additional measures of economic perceptions.
} 
TABLE 4

\section{Probability Effects for "Hypothetical" Latino Voter}

\begin{tabular}{|c|c|c|c|c|c|c|}
\hline & \multicolumn{3}{|c|}{ Cuban Americans } & \multicolumn{3}{|c|}{ Mexican Americans } \\
\hline & Democratic & Independent & Republican & Democratic & Independent & Republican \\
\hline Baseline & .32 & .21 & .47 & .78 & .16 & .06 \\
\hline Low Income & .32 & .21 & .48 & .78 & .15 & .06 \\
\hline High Income & .30 & .21 & .49 & .78 & .16 & .05 \\
\hline Men & .32 & .21 & .47 & .78 & .16 & .06 \\
\hline Women & .34 & .16 & .50 & .82 & .11 & .06 \\
\hline $\begin{array}{l}\text { Restrict } \\
\text { Abortion }\end{array}$ & .26 & .18 & .57 & .75 & .16 & .09 \\
\hline $\begin{array}{l}\text { Expand } \\
\text { Abortion }\end{array}$ & .38 & .24 & .38 & .80 & .15 & .04 \\
\hline $\begin{array}{l}\text { Restrict } \\
\text { Gov’t } \\
\text { Health } \\
\text { Insurance }\end{array}$ & .14 & .14 & .72 & .64 & .20 & .17 \\
\hline $\begin{array}{l}\text { Expand } \\
\text { Gov't } \\
\text { Health } \\
\text { Insurance }\end{array}$ & .53 & .23 & .24 & .87 & .11 & .02 \\
\hline
\end{tabular}

recompute the probability estimates. Thus, the difference between the baseline and the recomputed probability estimate gives the estimated impact of such a change in the independent variable on the hypothetical voter. ${ }^{12}$

The Republican campaign strategies discussed earlier are based on the assumption that Latino social conservatism and socioeconomic mobility will move them toward the Republican Party. There also have been questions as to whether newly naturalized Latinos have moved to register as Democrats in reaction to unpopular Republican leaders like Newt Gingrich or due to their substantive support of the Democratic party platform. To test these questions, we choose three variables for our probability estimates: income, attitudes toward abortion, and support of government-sponsored health care. We choose the first two variables because they are mentioned most often as key to Republican "conversion" strategies. We choose to look at support for government-sponsored health programs because, of the political issues in the model, we believe this issue most reflects the respondents' attitudes regarding the role of government in providing social services-

\footnotetext{
${ }^{12}$ Technically, we simply substitute the estimated coefficients and fixed values into the probability expressions presented above in note 6. This substitution allows us to produce an estimate of each probability for the assumed voter type. Changing one of the fixed values of the independent variables and recomputing the estimated probabilities gives us an estimate for the impact of that independent variable, given the values of the other independent variables. This has been called the "first difference" methodology (King 1998).
} 
one of the main philosophical differences between the Democratic and Republican parties. An analysis of the effect of this variable should give us some sense of how rooted Latino partisanship is in the actual ideological positions of the two parties.

Similar to our earlier findings, these probability estimates suggest that income does not have a significant effect on Latino partisanship. A movement from low income to high income results in no great change in either Mexican or Cuban party identification. This indicates that contrary to expectations, increases in Latino incomes should have little effect on Latino party identification.

Another issue that has been expected to move Latinos toward the Republican party is attitudes toward abortion. This does not seem to be the case among Mexican Americans. Mexican voters who decide they want to restrict abortion become only 3\% less likely to be Democratic and 3\% more likely to be Republican. Changes in attitudes toward abortion have more of an effect on Cuban partisanship, with those for restriction becoming $10 \%$ more likely to identify as Republican and those for expansion becoming $6 \%$ more likely to identify as Democrat. But given that socially conservative Mexicans are generally understood to be the group most likely to move to the Republican party because of their attitudes toward abortion, these findings suggest it is unlikely that will happen in the near future.

The one political issue that does seem to have an important effect on Latino partisanship is attitudes toward expansion or restriction of government health insurance. Mexicans who want to restrict government health insurance are almost three times as likely to identify as Republican and $14 \%$ less likely to identify as Democrats. Cubans, on the other hand, are $21 \%$ more likely to identify Democratic if they favor expansion of government health insurance and are $25 \%$ more likely to identify Republican if they are against it. Since government health insurance is an important social safety net, the fact that changes in attitudes about it have such a strong impact on party identification could mean that baseline Latino partisanship is predicated on particular philosophical attitudes toward the role and purpose of government. It could be that the baseline Mexican and Cuban identify with Democrats and Republicans, respectively, because they agree with those parties' philosophies about the role of government in society. This indicates that Latino partisanship may be philosophically "deeper" than generally has been assumed and that changes in Latino partisanship would require shifts in these basic positions about the role of government.

\section{Discussion and Conclusions}

While we do not have specific generational information for the new voters in this sample, our findings suggest that Latino partisanship evolves over time in the United States. Newer voters and younger Latinos seem to lean toward independence, while older Latinos have more established partisan attachments. As Latino voters become more socialized into the political system, they tend to move 
away from independence and toward the dominant party for their group - Democrats for Mexican Americans and Puerto Ricans and Republicans for Cuban Americans (Uhlaner and García 2001). The fact that this partisan identification is based on policy issue preferences indicates that unless the parties fundamentally change their issue positions, these Latinos' identifications with those parties should remain fairly stable.

Yet, this raises the question of why national origin should matter so much in this model, especially being of Cuban origin. In this case, national origin may be acting as a proxy for each group's political integration process. Cuban Americans have had a historically unique migration and settlement experience. They have been incorporated into American politics within particular political, institutional, and ideological constraints that have moved them strongly toward identification with the Republican Party (Moreno 1997). Mexican Americans and Puerto Ricans, on the other hand, have had historical experiences that have moved them toward the Democratic Party (Pycior 1997). This political experience could be what Latinos "learn" over time in the United States and could be replacing parental socialization as a way to transmit partisanship across generations (Niemi and Jennings 1991). Of course, once the parent is socialized into a particular identification, it is reasonable to assume the intergenerational transmission of that attachment will function much as it does in other communities, making Latino partisanship less variable over time and across generations.

One of the questions raised at the beginning of this article was the relative malleability of Latino party identification. Current party appeals to the Latino community reflect a general feeling that this group is "in play" politically. Given that over $40 \%$ of the Latino community is currently foreign born and that continued migration makes it likely that that proportion will remain fairly constant for the foreseeable future, our findings suggest that there will continue to be a large group of Latinos leaning toward independence or waiting to attach themselves to a political party. Yet, this is not to say that these Latinos are the equivalent of a political tabula rasa - our findings indicate that their eventual attachments will be defined by their policy preferences and the historical political experiences of their national origin groups.

Both the traditionalists and revisionists in the partisanship debate agree that there is a window of time within which party identification can change and that it tends to crystallize with age, but they disagree about the size and timing of that window. It could be that the particular nature of the Latino community in terms of nativity means that immigrant and younger Latinos have a larger window than the native born. Or it could be that the Latino community's unique generational makeup allows us to see a socialization process that has already occurred among Anglos and white ethnic immigrants. At the very least, comparative longitudinal studies of Anglo and Latino partisanship would be useful for tracking the evolution of this process.

We conclude that Latinos are an important group to use in the study of political beliefs and attitudes. Their experiences with the American social and 
political world have led to different dynamics in their acquisition of partisanship. Furthermore, there is considerable heterogeneity within the Latino community, across groups of different national origins and across generations. Much research remains to be done to understand how Latinos learn about the American political system and how that learning is translated from generation to generation.

\section{Appendix A: Variables and Coding}

Foreign Born:

Cuban:

Mexican:

Puerto Rican:

Married:

Some HS:

High School:

Some College:

2-yr. college:

4-yr. college:

$18-30$ :

31-45:

46-60:

60 and over

Women:

Catholic:

Spanish:

Spanish-English:

Abortion:

Illegal Immigration:

Affirmative Action:

School Vouchers: Gov't Health Ins:
$1=$ Foreign Born; $0=$ Native Born

$1=$ Cuban; $0=$ Not Cuban

$1=$ Mexican; $0=$ Not Mexican

$1=$ Puerto Rican; $0=$ Not Puerto Rican

$1=$ Married; $0=$ Not Married

$1=$ Some High School; $0=$ More Education

$1=$ Finished High School; $0=$ Did not finish or finished some college

$1=$ Some college; $0=$ Less or more education

$1=2$ year college or vocational school; $0=$ Less or more education

$1=4$ year degree or more; $0=$ Less education (excluded category in MNL analysis)

$1=$ aged $18-30 ; 0=31$ or older

$1=$ aged $31-45 ; 0=18-30$ or 46 or older

$1=$ aged $46-60 ; 0=$ younger than 46 or older than 60

$1=$ aged 60 and over; $0=$ younger than 60 (excluded category in MNL analysis)

$1=$ female; $0=$ male

$1=$ Catholic $; 0=$ another religion

$1=$ Spanish primary home language; $0=$ English or Spanish and English

$1=$ Spanish and English primary home language; $0=$ other language

$2=$ Abortion should be easier to obtain; $1=$ stay the same; $0=$ be more restricted

$2=$ U.S. government doing too much; 1 = right amount;

$0=$ not doing enough

$2=$ Programs should be expanded; 1 = programs should be continued; $0=$ programs should be reduced

$1=$ opposed; $0=$ in favor

$1=$ in favor; $0=$ opposed 
$\begin{array}{ll}\text { Budget-Tax cut: } & 1=\text { in favor; } 0=\text { opposed } \\ \text { Budget-Debt: } & 1=\text { in favor; } 0=\text { opposed } \\ \text { Budget-Domestic: } & 1=\text { in favor; } 0=\text { opposed }\end{array}$

Guns:

Additive scale of responses to four questions about gun control: 1 = favor; 0 = oppose. The four questions concerned: (a) a nationwide ban on people carrying a concealed weapon; (b) requiring trigger locks to be sold with all new handguns; (c) requiring people to get a license in order to legally own a handgun; and (d) requiring all handgun owners to attend a course on gun safety. We verified the linear scale in three ways. First, a simple principal factor analysis demonstrated that all four gun control questions had roughly similar factor loadings: $.42528, .58439, .55258$, and .54143, respectively. Second, we computed the Cronbach's alpha reliability statistic to compare the correlation between the scale we use and the underlying factor; the alpha statistic is .6379 , and the square root of the alpha statistic is .7987, showing a strong correlation between the gun control scale and the underlying factor. Third, we computed the item-test correlations for each gun control item (the correlation between the particular item and the additive scale) and the item-rest correlations (the correlation between each item and an additive scale formed from the remaining items). Both sets of correlations show evidence that our additive scale is appropriate: the item-test correlations are $.6397, .7373, .7085$, and .6982, respectively; the item-rest correlations are $.3367, .4784, .4315$, and .4123 , respectively.

Liberal:

Conservative:

$1=$ Liberal; $0=$ Conservative or Moderate

$1=$ Conservative; $0=$ Liberal or Moderate

$1=$ Did not vote in 1996 presidential election; $0=$ Did vote

Economic Percept: $\quad 1=$ family situation improved in past four years; $0=$ stayed the same or got worse

Income:

$7=$ More than $\$ 100,000 ; 6=\$ 75,000$ to less than $\$ 100,000 ; 5=\$ 50,000$ to less than $\$ 75,000 ; 4=\$ 35,000$ to less than $\$ 50,000 ; 3=\$ 25,000$ to less than $\$ 35,000$; $2=\$ 15,000$ to less than $\$ 25,000 ; 1=$ less than $\$ 15,000$

Manuscript submitted 16 April 2001

Final manuscript received 16 November 2001 


\section{References}

Abramson, Paul R., and Charles W. Ostrom. 1991. "Macropartisanship: An Empirical Reassessment." American Political Science Review 85(1): 181-92.

Aldrich, John H., and Forrest D. Nelson. 1984. Linear Probability, Logit, and Probit Models. Newbury Park, CA: Sage.

Alvarez, R. Michael. 1990. “The Puzzle of Party Identification.” American Politics Ouarterlv 18(4): 476-91.

Alvarez, R. Michael, and Garrett Glasgow. 2000. "Two-Stage Estimation of Nonrecursive Choice Models." Political Analysis 8(2): 147-66.

Box-Steffensmeier, Janet M., and Renée M. Smith. 1996. "The Dynamics of Aggregate Partisanship." American Political Science Review 90(3): 567-80.

Brischetto, Robert. 1987. "Latinos and the 1984 Election Exit Polls: Some Findings and Some Methodological Lessons." In Ignored Voices: Public Opinion Polls and the Latino Community, ed. Rodolfo de la Garza. Austin: CMAS Publications, University of Texas.

Cain, Bruce E., D. Roderick Kiewiet, and Carole J. Uhlaner. 1991. "The Acquisition of Partisanship by Latinos and Asian Americans." American Journal of Political Science 35(2): 390-422.

Campbell, Angus, Philip E. Converse, Warren E. Miller, and Donald E. Stokes. 1960. The American Voter. New York: John Wiley and Sons.

de la Garza, Rodolfo O., F. Chris García, and Louis DeSipio. 1992. Latino Voices: Mexican, Puerto Rican, and Cuban Perspectives on American Politics. Boulder, CO: Westview Press.

DeSipio, Louis. 1996. Counting on the Latino Vote: Latinos as a New Electorate. Charlottesville, VA: University Press of Virginia.

Fiorina, Morris. 1981. Retrospective Voting in American National Elections. New Haven: Yale University Press.

Franklin, Charles H. 1984. "Issue Preferences, Socialization and the Evolution of Party Identification." American Journal of Political Science 28(3): 459-78.

Franklin, Charles H., and John E. Jackson. 1983. "The Dynamics of Party Identification.” American Political Science Review 77(4): 957-73.

García, F. Chris, and Rodolfo O. de la Garza. 1977. The Chicano Political Experience: Three Perspectives. North Scituate, MA: Duxbury Press.

García Bedolla, Lisa. 1999. "Fluid Borders: Latino Identity, Community and Politics in Los Angeles." Ph.D. diss., New Haven: Yale University.

Green, Donald Philip. 1988. "On the Dimensionality of Public Sentiment Toward Partisan and Ideological Groups.” American Journal of Political Science 32(3): 758-80.

Green, Donald Philip and Bradley Palmquist. 1990. "Of Artifacts and Partisan Instability." American Journal of Political Science 34(3): 872-902.

Greene, William H. 2000. Econometric Analysis, 4th ed. Upper Saddle River, NJ: Prentice Hall.

Hero, Rodney. 1992. Latinos and the U.S. Political System: Two-Tiered Pluralism. Philadelphia: Temple University Press.

King, Gary. 1998. Unifying Political Methodology. Ann Arbor: University of Michigan Press.

Kosmin, Barry A., and Ariela Keysar. 1995. "Political Party Preferences of U.S. Hispanics: The Varying Impact of Religion, Social Class and Demographic Factors." Ethnic and Racial Studies 18(2): 336-47.

Long, J. Scott. 1997. Regression Models for Categorical and Limited Dependent Variables. Thousand Oaks, CA: Sage.

Markus, Gregory B., and Philip E. Converse. 1979. “A Dynamic Simultaneous Equation Model of Electoral Choice." American Political Science Review 73(4): 1055-70.

McKuen, Michael B., Robert S. Erikson, and James A. Stimson. 1989. "Macropartisanship." American Political Science Review 83(4): 1125-42.

Miller, Warren E. 1991. "Party Identification, Realignment and Party Voting: Back to the Basics." American Political Science Review 85(2): 557-68. 
Miller, Warren E., and J. Merrill Shanks. 1996. The New American Voter. Cambridge: Harvard University Press.

Moreno, Dario. 1997. "The Cuban Model: Political Empowerment in Miami." In Pursuing Power: Latinos and the U.S. Political System, ed. F. Chris García. Notre Dame: University of Notre Dame Press.

Nicholson, Stephen P., and Gary M. Segura. 2001. "Agenda Change and the Politics of Latino Partisan Identification." Paper presented at the Minority Representation: Institutions, Behavior and Identity Conference, Claremont Graduate University.

Niemi, Richard G., and M. Kent Jennings. 1991. "Issues and Inheritance in the Formation of Party Identification." American Journal of Political Science 35(4): 970-88.

Page, Benjamin I., and Calvin Jones. 1979. "Reciprocal Effects of Policy Preferences, Party Loyalties, and the Vote." American Political Science Review 73(4): 1071-89.

Pycior, Julie. 1997. LBJ and Mexican Americans. Austin: University of Texas Press.

Uhlaner, Carole J., and F. Chris García. 2001. "Learning Which Party Fits: Experience, Ethnic Identity, and the Demographic Foundations of Latino Party Identification." Paper presented at the Minority Representation: Institutions, Behavior and Identity Conference, Claremont Graduate University.

Uhlaner, Carole J., Mark M. Gray, and F. Chris García. 2000. "Ideology, Issues and Partisanship among Latinos." Paper presented at the annual meeting of the Western Political Science Association, San Jose, California.

Welch, Susan, and Lee Sigelman. 1993. "The Politics of Hispanic Americans: Insights from National Surveys, 1980-1988.” Social Science Quarterly 74(1): 76-94.

R. Michael Alvarez is associate professor of political science, California Institute of Technology, Pasadena, CA 91125-7700.

Lisa García Bedolla is assistant professor of political science and Chicano/ Latino studies, University of California, Irvine, CA 92697-5100. 